$\frac{1}{2}$ per cent., and most recently in method (1) sterile water. The urea and quinine hydrochloride requires a little longer to act, but its effect is more prolonged than that produced by novocain, otherwise there is nothing to choose between them; whilst for an intradermic injection, water alone is porfectly satisfactory. At first we were doubtful of the action of this anaesthetic on the vitality of the grafts, but even when transferred direct to the wound they took perfectly, although as a matter of convenience in handling, we, as a rule, put them first into warm saline.

The advantages of a local over a general anaesthetic for this purpose are obvious. There is no need of an assistant, of previous preparation of the patient, or of moving the patient from his becl. In the eycs of the patient it appears a much more tritling business-an important point if it has to be done frequently, as in the case of large wounds, or repeated if the first grafts fail to take. Lastly, perliaps, if ono can skin-graft with no more trouble than doing a dressing, one will be inclined to graft even small wounds, which would heal perfectly well with. out it, but in which, nevertheless, a week or ten days can thereby be saved.

\section{GAS GANGRENE AND TETANUS.}

W. K. IIATCII, F.R.C.S., Lieut.-Col. I.M.S.(Ret.), LATE SLNTOR SURGEON, SIK JAMSETJEE JEEJEEBHOY HOSPITAL, BOMBAT.

So-CALLED gas gangrene is not infrequently met with in civil practice in tropical climates, which afford conditions favourable to the growth of germs. My experience of this disease was derived from cases occurring in the wards of the Sir Jamsetjee Jeejeebhoy Hospital, Bombay, between the years 1882 and 1902, and also from cases outside the hospital. 'The conditions favourable for the rapid growth of germs of every kind are crer present in Bombay -nameiy, moist lieat aud dirt; these conditions were probably more than usually favourable in France owing to the hot dry summer by which the ground was much licated, followed by lieavy rains.

In Bombay many patients developed gangrene after admission, others were admitted with the disease more or less established; in some applications of earth, cow-dung, ctc., had been made by way of treatment to the injurcd part; in others the wounds appeared clean and healthy. I do not remember to have met with the gangrene after an opcration. I am quite certain, however, that this disease was more common in the earlier years, between 1883 to 1892, than later, when wounds were treated by more active antiseptic measures. Frequently quite slight injuries, comparatively speaking, and notably Colles's fracture, witl only a few superficial abrasions of the skin, werc followed by gas gangrene; in onc case, in which the disease appeared in the scrotum and spread rapidly to the perineum and upwards to the abdomen, no injury of any kind was visible to the naked eye; this patient died in two days. It is a curious fact that I have never seen gas gangrene occur after scalp wounds, many of which werc of a very extensive nature, as in the riots in Bombay on two occasions, thougl in a very foul condition from contact with dirt from tho streets; many of these patients were attacked by tetanus of very severe type.

Amputation was the treatment always adopted for gas gangrene, but it is by no means necessary to amputate above the crepitating arca, provided that the deeper parts are not involved and flaps can be made from crepitating skin. As an instance I may mention the case of a boy admitted with a gangrenous arm, crepitation being present over the whole of the front of the chest. The question of amputation was discussed, and I advised it strongly on the strength of my experience in former cases; it was performed at the shoulder-joint, and the patient made a good recovery.

At the time of operation iodoform was always rubbed freely into the flaps and the face of the stump; no sutures were employed, but a large drainage tube was placed across and dry dressings loosely applied, no bandage being used. This is important on account of the likelihood of secondary haemorrhage. I well remember one case in which the axillary artery suddenly began to bleed on the day following operation. Fortunately the house-surgeon was at the next bed; he quickly removed the dressings and applied a pair of haemostatio forceps, which were left in situ for several days. After removal no further haemorrhage took place.

Tetanus, too, is an extremely common disease in Bombay, and it seemed to me that the most acute cases were met with before and after the rainy season. All methods of treatment except injection of magnesium sulphate and elevation of trunk and legs were tried by the staff. If the type of cases was severe no one method gave better results than another. The milder cases met with during the cold season gave equally good results by all methods. Therefore I conclude that the severity of the case is really the deciding point in the restult.

At the request of a member of the Plague Commission we tried the injection of antitetanic serum into the brain. ' $T$ 'wo serious cases were selected; in both it seemed to me the severity of the symptoms was increased, and both died; but death, I think, would certainly have occurred whatcrer treatment had been adopted.

There appears to be a cyclical increase in the number and severity of tetanus cases, as is seen also in plague.

Infected wounds" of all kinds were usually treated by mo with pure carbolic acid, which I rubbed freely into the wound; this was always done for bites and claw wounds of wild animals and dogs. In the case of dog bites the wounds were also excised, when possible, and carbolic acid again applied. I have never secn any bad result from the application of carbolis acid to such wounds, or any cases of hydrophobia follow in patients in whom the bites were thus treated, although in several instances that the dogs were mad was subsequently proved by post-morten. examinations.

'The statements made recently of the danger of applying pure carbolic acid to infected wounds appear to me to be quite groundless.

\section{THE TREATMENT OF PAINFUL “ FROST-BITE."}

BY

W. CIIARLES DAVIS, L.R.C.P. AND S.EDIN., DAVID LEWIS NORTHERN HOSPITAL, LIVIERPOOL.

The problem of how best to treat painful frost-bitten feet is one which doubtless has caused those in charge of military wards some anxiety. The best remedy I have found to be cocainae gr. viii, ol. olivae $z^{i v}$, liq. calcis $z^{i r}$, which simply means carron oil and cocaine. A small quantity is rubbed into the feet twice daily, special attention being given to the toes; the feet are massaged with it for a few minutes, and afterwards wrapped up in cotton-wool. It is an improvement to add $1 \mathrm{oz}$. of liquid paraffin to $4 \mathrm{oz}$. of carron oil, as by this addition it is prevented from oxidizing so quickly, and also from drying up so rapidly, and makes it less liable to rancidity. When the oil dries on the feet, the following dusted on is an excellent powder: Camphor gr. xxxv, zinc oxide and pulv. amyli àă $\bar{s} s \mathrm{~s}$.

In all my recent casos in which there has been no ulceration this form of treatment has been entirely successful; one advantage is that the patient is able to sleep without any narcotic.

When the acute stage passes off the carron oil and cocaine is mixed with equal parts of carbolic oil, the percentage of which is increased as the pain decreases.

Another very important consideration is the fact that the men can be the more quickly put on the convalescent list, thereby enabling them to get back sooner to the front.

THE late Flect-Surgeon Godfrey Taylor, R.N., who was lost in the rormidable on January 1st, left unsettled personal estate in the United Kingdom £4,366.

SOME idea of the capabilities of British Columbia is afforded in a short report by the inspector on the production of honey. It appears that the total crop, which was 50 tons in 1913, was between 150 and 200 tons in 1914. It is true that 1913 was a bad, and 1914 a good, honey year, but evidence is given to show that the results may be greatly improved even in bad years. 